\title{
15
}

\section{ONLINE WRITTEN \\ ARGUMENTATION}

\author{
Internal dialogic features \\ and classroom instruction
}

\section{Naomi Rosedale, Stuart McNaughton, Rebecca Jesson, Tong Zhu, and Jacinta Oldehaver}

\section{Summary}

In this chapter, we draw from a study involving a 1:1 digital initiative in Auckland, New Zealand, to consider the impact of an Argumentation Tool (AT) on students' discussion board posts. We examine use of the AT, integrating Google Groups and competing text evidence, to support development of internally dialogic argumentation important for reasoning, critical thinking, and perspective taking. Cross-sectional data is analyzed from nine primary schools including 38 observations and 342 student posts by applying a profiling taxonomy. Use of the AT shows an emerging relationship between argumentation focused instruction and development of perspective integration in students' writing. Findings suggest the AT supports diagnostic assessment of internally dialogic argumentation and promotion of perspective taking as important 21st-century skills.

\section{Introduction}

A group of cognitive and social skills (perspective taking, collective problem solving, creativity and critical thinking) is claimed to be increasingly significant for successful living in the 21st century. Variously described as 21st-century skills (National Research Council, 2012) and key competencies (OECD, 2015), they are identified in many curricula round the world as important foci for national education systems (García, 2016; Voogt \& Roblin, 2012).

There are several rationales for why we should focus on teaching these 21st-century skills, including the need for an informed and critically engaged civil society made more urgent in digital environments. Opinions can be manipulated through the rapid and extensive access to online information and the use of social media platforms. Self-perpetuating and reinforcing systems of knowledge 
can be created where misinformation, inaccuracies or untruths are taken as truth through repetition and support within social networks. For example, computational propaganda, with algorithms, automation, and human curation are being designed to purposefully distribute misleading information and increasingly influence popular decision making (Woolley, Philip, \& Howard, 2017). Civic decisions, as well as judgments and complex health and science issues, are increasingly susceptible to these influences.

In keeping with the concept of being pertinent for the 21st century, there are also relationships between these skills and post-school outcomes such as the changing nature of work, although there are limitations in the evidence base of the degree to which we can attribute direct causal relationships (National Research Council, 2012). The relationships include benefits to the individual in terms of employability because skilled work now requires such skills and these skills contribute to mental health and well-being. Similarly, there are benefits to society from a more productive and cohesive citizenry (García, 2016; Roberts, Martin, \& Olaru, 2015).

Argumentation, or critical reasoning, involves a set of knowledge and skills identifiable under the rubric of 21st-century skills and of critical importance in the development of higher-order thinking. Along with critical thinking and critical literacy, argumentation provides a means to make reasoned judgments (Rapanta, García-Mila, \& Gilabert, 2013), but has wider significance, including assisting students to conceptualize and filter information, make connections across contexts, enhance their abilities to communicate knowledge (Kuhn, 1991, 2005) and integration of alternative viewpoints.

Developing expertise in argumentation necessarily implies perspective taking and aspects of cognitive and emotional empathy, but there is less evidence for these assumed generalized impacts on social and emotional skills. However, there are experimental demonstrations of building practices for a "community of learners" in argumentation and collaborative reasoning which include these skills in different subject areas such as science (Rapanta et al., 2013), and English language arts (Brown, 2016). These instructional designs include a focus on the interpersonal and intrapersonal skills necessary to engage effectively in the practices of face-to-face communities. Less is understood about how argumentation impacts cognitive and social skills in online environments and the notion of internal dialogism: features necessary for attending to and integrating alternative perspectives to inform belief and decision making. Kuhn and colleagues (2014) make a distinction between the skills required for individual argumentive writing and dialogic argumentation between individuals "personified by a flesh-andblood other." Advocating for student development of dialogic focus the authors maintain that effective thinking involves internal integration of others' positions, such as counter arguments and taking into account "the framework of alternatives" (Kuhn, Hemberger, \& Khait, 2014, p. 43).

Thinking with a dialogic focus is arguably far more complex and challenging for young people not least because alternative positions have to be imaginatively 
conjured, held in creative tension (Wegerif, 2013) and reasoned independently. In online contexts such as forums, blogs and instant messaging (IM), argumentation with dialogic focus is an increasingly important skill when participating in uncensored global communities, for maintaining well-being and contributing or consuming content. The intellectual skills of counter, rebuttal, acknowledging alternative evidence and self-correction are features of an internalized awareness of "other" ways of knowing and the incomplete nature of personal knowledge. To formalize the notion of dialogic focus (in the absence of a conversation partner), we will refer to these features as internally dialogic markers within written argumentation.

Incorporating the use of digital tools in classrooms, such as communication platforms and diagnostic applications, offers opportunities to investigate the internally dialogic nature and development of student argumentation for improved thinking and communicating. For example, Kuhn and Crowell (2011) report dialogic argumentation with middle-schoolers using online IM, citing much improved direct counterargument over 3 years. One of the observed benefits of using IM applications was the ability to engage reflectively with transcripts of the written exchanges. Saltarelli and Roseth (2014) showed that cooperation can be enhanced in a digital version of "constructive controversy," a cooperative learning procedure involving dialogic argumentation which has the goal of reaching and raising awareness of an integrated position. However, incorporating argumentation with classroom curriculum is said to require thoughtful planning (Howell, Butler, \& Reinking, 2017) and found to present pedagogical challenges, which include use of multi-modal evidence (Hutchison \& Reinking, 2010) and teacher emphasis on internet inquiry skills over engagement with other viewpoints (Purcell, Heaps, Buchanan, \& Friedrich, 2013).

\section{The development of internally dialogic argumentation: Function and profile}

To examine the developmental features of argumentation, Kuhn and Crowell (2011) have developed a taxonomy of functional moves children can make. The framework is based on idea units: essentially a statement that carries a single claim supported by a reason. Each idea unit has one of four functions, namely: support one's own position, counter an alternative position, acknowledge weakness in one's own position, and acknowledge or consider the strengths in an alternate position. The development of ideas can be examined in two ways. One is to look at the sheer number of these different forms across ages. A second is to consider each child's overall argument in terms of three developmental profiles (Kuhn \& Crowell, 2011). A Single profile only contains ideas that support one's own position. A Dual profile has these types of ideas but also contains one or more ideas that critique positions other than one's own. The third profile represents arguments that are Integrated; they contain ideas that consider the merits of other positions, and/or the weakness in one's own with the purpose of weighing 
TABLE 15.1 Descriptions of Argumentation Profile by Argumentation Function

\begin{tabular}{ll}
\hline Profile & Functions of argumentation \\
\hline $\begin{array}{l}\text { Single profile } \\
\text { Dual profile }\end{array}$ & $\begin{array}{l}\text { ideas that advance own position only, i.e., one direction } \\
\text { ideas that include critique of alternative positions, i.e., critique often } \\
\text { aims to advance own position by identifying drawbacks in the other } \\
\text { position }\end{array}$ \\
$\begin{array}{l}\text { ideas that integrate the strength in an alternate position(s) or a } \\
\text { weakness of own position }\end{array}$ \\
\hline
\end{tabular}

these up in drawing conclusions. For clarity, Table 15.1 outlines each of the three profiles in order of progression alongside the associated functions:

In a three-year longitudinal study, the taxonomy was used to determine profiles of 6th-8th grade students' written argumentation (Crowell \& Kuhn, 2014; Kuhn \& Crowell, 2011). The majority of students participating in a dialogic argumentation curriculum began to make dual perspective arguments by the end of the first year but integrated arguments did not emerge until the third year. By contrast, comparison-group students, in an essay-style, whole class discussion condition, showed no evidence of gains in either respect. Earlier research supports these findings, that without intervention, young adolescents typically concentrate attention on exposition of their own claims, ignoring other positions (Kuhn \& Udell, 2003; Kuhn, Goh, Iordanou, \& Shaenfield, 2008). In other words, it is likely students are either uninformed of the value of perspective taking in their communication or are constrained by the context, including social norms of the classroom.

\section{Teaching dialogic argumentation skills}

Much of what we know about the teaching of argumentation comes from science-based fields that promote learning through evidence-based claims (Song, Deane, Graf, \& van Rijn, 2013). Rapanta et al. (2013) distinguish between an "arguing to learn" approach premised upon the idea of content learning resulting from engagement in argumentation and a "learning to argue" approach which focuses on the development of argument skills. Both approaches have been widely employed. Much less is understood of how to develop dialogic focus, particularly in online discourse, where the critical integration of perspectives and alternative evidence require targeted practice and instruction.

Recent research on classroom designs to increase argumentation and reasoning indicate that dialogue intensive pedagogy can contribute to valued student outcomes, such as comprehension, perhaps better than other instructional designs (Wilkinson \& Son, 2010; Reznitskaya et al., 2001). The design of Collaborative Reasoning focuses on learning from each other in the process of arguing and the development of argument schema. The dialogic forms go beyond adversarial and coalescent forms because they are embedded in activities in which positions are modified in light of the arguments. 
Given the need for deliberate socialization, it is not surprising to find low levels of argumentation and weak skills reported across grade levels and disciplines (Kuhn, Wang, \& Li, 2011). Litman and Greenleaf (2017) identified just 24 argumentation tasks in 40 lessons with 18 volunteer teachers, all of whom had been recruited as experienced in developing disciplinary literacy and had been long term partners in a design-based research project in argumentation. Nevertheless, the majority of the tasks had incipient forms of productive argumentation in which students worked collaboratively to identify and evaluate possible meanings or positions.

\section{Research design}

We designed an argumentation tool (AT) as part of a wider project Developing in Digital Worlds ${ }^{1}$ to better understand how school-wide digital environments might promote 21 st-century skills. The 4-year project is located in a 1:1 digital initiative in primary and secondary urban schools $(n=16)$ in New Zealand, serving mostly Māori (indigenous) and Pasifika (from Pacific Islands) families from low socioeconomic status (SES) communities. Schools employ a range of digital tools, to achieve valued student outcomes and the pedagogy promotes "digital citizenship" inside and outside of the classroom.

We developed the AT as a classroom instructional resource and an assessment instrument. In what follows we describe its development and provide evidence of argumentation instruction in classrooms including how the AT can establish a link between instruction and the development of student perspective taking (the internally dialogic features of student written argumentation).

Data were collected at two time points 18 months apart. These provided independent samples of teachers in different classrooms using the AT. Alternate forms of the AT were used at these times to test the flexibility of the tool and how it could be used for reliably coding features of argumentation in different forms. We could also check its sensitivity to instructional focus of the teachers. Thirtyeight classrooms in the primary schools participated.

\section{Description of the method}

\section{The Argumentation Tool (AT): Providing a context for internally dialogic argumentation}

The AT positioned students as first responders to a Google Groups discussion board. Students were required to adopt an independent, but dialogic focus in response to the topic provocation and hyperlinks to corresponding media resources. The topic provocation emulated the "voice" of a would-be discussant, and the hyperlink to contradictory online evidence. This was embedded in a teacher resource which included a PowerPoint presentation introducing the provocation, activity instructions and hyperlinks to the evidence documents and discussion board. ${ }^{2}$ 
The first form of the AT proposed an issue related to a recent event in New Zealand online media. The issue was considered highly topical for young people at the time and concerned a visiting celebrity, and a local production crew filming a music video at a local beach. Bethels Beach has a protected area for native Dotterels, an endangered bird species, which is controlled by the New Zealand Department of Conservation and requires a permit regulating use of the beach. The local film company were reported to have disregarded the regulations, transporting equipment and personnel (including the famous song star) in 12 vehicles instead of the mandated two. The online discussion board topic stated: "Taylor Swift should have treated the beach with more respect."

The second featured a different environmental issue. The New Zealand government's Predator Free 2020 campaign seeks to eradicate all animal and insect pests (e.g., rats, stoats, feral cats, possums) considered a threat to native wildlife. The targeted pests are listed on the Department of Conservation website and contain some species of potential concern such as eradication of certain introduced horse breeds and wild hares. Extreme Predator Free groups are calling for the long-term ban on cats and interim curfews. Figure 15.1 provides a screenshot of the second version of the discussion board which states: "Predator Free groups should treat 'pests' with more respect."

A slide presentation with the activity instructions was read out to the students by the teacher and a copy was shared with students via email (or a class website). The assignment guidelines given to teachers included reading through the instructions with the whole class, answering any questions and being on hand to give support with reading comprehension. Teachers were required to share with the class any questions raised in their one-on-one interactions, so that all students benefitted equally from any advice.

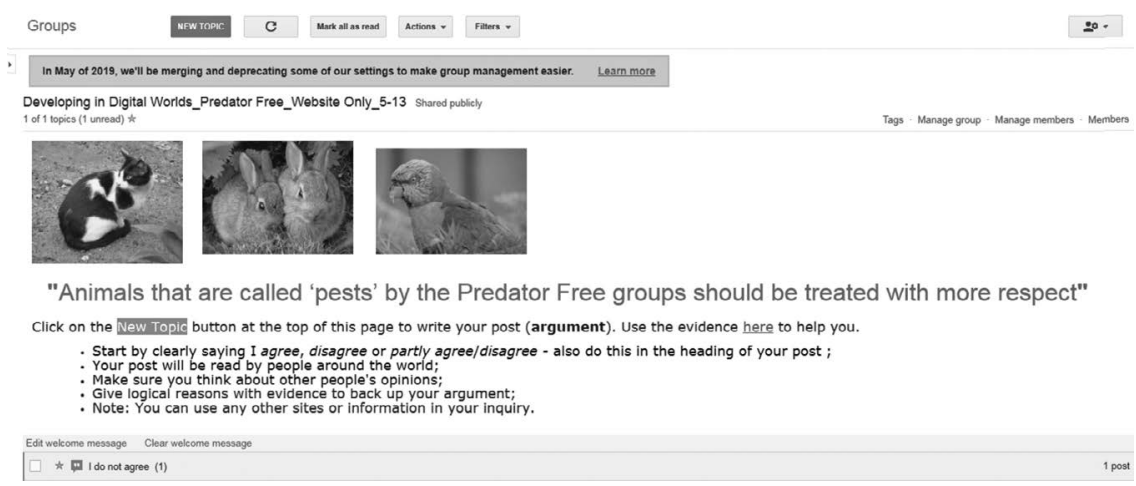

FIGURE 15.1 Discussion board with link to evidence document at Time 2 .

Source: "Creative Commons Gato callejero en Madrid 02.jpg, Wild Rabbits at Edinburgh Zoo.jpg and (1)Rainbow Lorikeet 074a.jpg" used under the CC Attribution-Share Alike 2.0 Generic license / Desaturated from originals. 
After reading the evidence sheet, students were given thirty minutes to post their response to the Google Groups discussion board. While composing their individual response, they were unable to see any of the other responses as Google Groups opens a separate window instance during composing, and the discussion thread is not updated until after selecting the "Post" option. Teachers were encouraged to invite students to read and respond to one another's responses, in a subsequent lesson. Students were not permitted to edit their contribution once posted to the discussion board, but editing could be undertaken prior to final posting.

All of the classrooms were given the same prompt posted by a fictitious discussant (e.g., MusicBot; Naturelover). Students were asked to post their written response supported by guidelines including: "Start by clearly saying - I agree, disagree or partly agree/disagree; remember that your post will be read by people around the world; make sure you think about other people's opinions when you reply; give good reasons and think logically; you can use other sites or information on the Internet to help you."

Reference material in the form of a hyperlink to an evidence sheet provided brief summaries of the event from four different sources: a national newspaper (the New Zealand Herald), Department of Conservation, YouTube, and Kiwi Kids News (an online news website for young New Zealanders). Each source offered confirmatory or conflicting evidence. The evidence document and assignment instructions were composed to ensure age appropriate readability and the original source texts could be accessed if students followed up with an online search.

\section{Classroom observations}

We also observed practices in classrooms. The 38 teachers (20 at Time 1 and 18 at Time 2) were observed teaching a nominated "21st-century skill" and nine of the teachers specifically nominated argumentation. We observed the teacher interacting with students in a 3-minute interval and alternated that with checking what the students were doing, singly or together with their devices ( 3 minutes) as they worked away from the teacher. Observers recorded field notes for one minute after the teacher focus ( 3 minutes) and student focus ( 3 minutes) for a total of 8 -minute intervals. Each classroom observation totaled 48 minutes (6 intervals). The observation schedule coded each interval for the presence of argumentation sub-skills such as a claim, warrant, evidence, and conclusion. ${ }^{3}$ We analyzed 132 intervals at Time 1 and 89 intervals at Time 2 . In observations using two observers we determined inter-rater reliability was above $90 \%$ at each time point.

The observations enabled us to identify classrooms where there was a relatively high explicit focus by the teacher on the sub-skills involved in argumentation (a focus on any one of the sub-skills was explicitly observed in at least one interval; $n_{T 1}=8, n_{T 2}=9$ ) or a relatively low explicit focus on argumentation skills (no explicit focus was observed $n_{T 1}=12, n_{T 2}=9$ ). 


\section{Data analysis}

Google Groups offers a downloadable summary of written posts, including date and time stamp, email identity of the correspondent and content of the individual responses posted to the discussion thread. Each classroom audit from Google Groups was checked against the online discussion board and used to transfer written responses into an Excel database.

Written posts by students were each subjected to a word count, segmented into idea units, and units classified into one of four categories from Kuhn and Crowell's (2011) scheme. Each idea unit was blind coded by its function; M+ (idea supporting one's own position), O- (idea that critiques alternate position), $\mathrm{M}$ - (acknowledges weakness in own position), O+ (acknowledges strengths of an alternate position). Verbatim examples are provided in Table 15.2.

In addition, each student's developmental profile was categorized as one of the three argumentation profiles according to the set of their argumentation functions (as described in Table 15.1). An Integrated profile featuring $\mathrm{M}$ - idea units are rare phenomenon, considered developmentally challenging even for adults (Kuhn et al., 2014).

\section{Existing practices}

\section{Students' online argumentation}

A total of 470 and 716 idea units were coded at Time 1 and 2 respectively. As explained earlier, we coded each idea unit by its function and in turn determined student argumentation profiles.

The distributions of the four types of function in idea units are shown in Figure 15.2. Almost three quarters of the idea units $(n=1186)$ were Single $(\mathrm{M}+)$, adopting a position and supporting that position (74.3\% at Time 1 and $71.1 \%$ at Time 2). $11.7 \%$ (Time 1) and $8.8 \%$ (Time 2) of the idea units were coded Dual in that they provided a critique of an alternate position (O-). Shifts in percentages of ideas in Single and Dual profiles resulted in increased Integrated profiles, ideas recognizing the worth of the alternative position $(\mathrm{O}+)$ and/or the weakness of one's own (M-). Chi-squared test of independence indicated that changes in the distributions of ideas by argumentation function and profile were statistically significant at $5 \%\left[\chi^{2}(2, n=1186)=9.20, p<.05\right]$.

The Single profile follows a curvilinear pattern across age, increasing to a point of inflection at 10 years (Year 6) and at an average number of almost three ideas. Students' Integrated profiles also have a curvilinear pattern with a change in growth curve at 10 years, similar to the development of single perspective but at a much lower average frequency; close to one idea unit on average (see Figure 15.3). Although the Dual profile has a similar pattern, emerging at the same age as the Integrated, the number of ideas per post are far less (much lower than one idea unit on average). Therefore, even though change in development of perspective taking profile occurs at the same age 
TABLE 15.2 Coding scheme for the AT discussion board posts

\begin{tabular}{|c|c|c|}
\hline Argument type & $\begin{array}{l}\text { Agrees. Taylor Swift Should } \\
\text { Have Treated the Beach with } \\
\text { More Respect }\end{array}$ & $\begin{array}{l}\text { Disagrees. Taylor Swift Treated the } \\
\text { Beach with Respect }\end{array}$ \\
\hline No argument & $\begin{array}{l}\text { "Taylor should have treated } \\
\text { the beach with more } \\
\text { respect." Year } 3 \text { student (age 7) }\end{array}$ & $\begin{array}{l}\text { "I disagree because she treated the } \\
\text { beach just fine." Year } 4 \text { student } \\
\text { (age 9) }\end{array}$ \\
\hline $\begin{array}{l}\text { Own-perspective } \\
\text { only (includes } \\
\text { only positives of } \\
\text { preferred option): } \\
\text { Single profile }\end{array}$ & $\begin{array}{l}\text { "I agree because Taylor Swift } \\
\text { was told to come with } 2 \\
\text { vehicles but her crew came } \\
\text { with } 12 \text { vehicles so she } \\
\text { disrespected New Zealand } \\
\text { by not listening [M+1]." Year } \\
8 \text { student (age 11) }\end{array}$ & $\begin{array}{l}\text { "I agree that Taylor should have } \\
\text { treated the beach with more } \\
\text { respect when she was making her } \\
\text { video at the beach in New } \\
\text { Zealand because her crew was } \\
\text { only allowed to take two trucks } \\
\text { but instead she took } 12 \text { trucks } \\
{[M+1] \text { and could damage the rare }} \\
\text { bird, the dotterels and their nests } \\
{[M+2] . " \text { Year } 4 \text { student (age 9) }}\end{array}$ \\
\hline $\begin{array}{l}\text { Dual perspective } \\
\text { (includes } \\
\text { negatives of other } \\
\text { option): Dual } \\
\text { profile }\end{array}$ & $\begin{array}{l}\text { "She could have said } \\
\text { something to the film } \\
\text { people [O-1]. The trucks } \\
\text { would have upset the } \\
\text { creatures [M+1]." Year } 5 \\
\text { student (age 9) }\end{array}$ & $\begin{array}{l}\text { "I disagree that Taylor swift did } \\
\text { not respired [sic] our country and } \\
\text { the beach because she was } \\
\text { complementing it and saying that } \\
\text { it was the best beach that she has } \\
\text { ever been to [M+1] ... If Taylor } \\
\text { swift did not respect our beach } \\
\text { then she would not have posted } \\
\text { the music video [O-1]." Year } 7 \\
\text { student (age 11) }\end{array}$ \\
\hline $\begin{array}{l}\text { Integrative } \\
\text { perspective } \\
\text { (includes positives } \\
\text { of other option } \\
\text { or negatives of } \\
\text { preferred option): } \\
\text { Integrated profile }\end{array}$ & $\begin{array}{l}\text { "Taylor Swift messed up the } \\
\text { beach by bringing too many } \\
\text { cars because her crew } \\
\text { damaged bird nests with all } \\
\text { their trucks [M+1]. She } \\
\text { should have known better } \\
\text { [O-1]. But she did get a } \\
\text { video out to the world that } \\
\text { shows off our beach [O+1] } \\
\text { and maybe she didn't even } \\
\text { know about the contract } \\
\text { [O-1]." Year } 8 \text { student (age 12) }\end{array}$ & $\begin{array}{l}\text { "I'm in the middle because I think } \\
\text { that yes it was bad about that she } \\
\text { might have scared the birds } \\
{[M+1] \text {. And she brought } 12 \text { cars }} \\
\text { when she was only allowed } 2 \\
{[M+2] \text {. But she did promote NZ }} \\
\text { beaches [O+1] and our film } \\
\text { company [O+2]. Since she } \\
\text { prompted [sic] us tourists will } \\
\text { come so that's a positive O+3." } \\
\text { Year } 6 \text { student (age 10) }\end{array}$ \\
\hline
\end{tabular}

(10 years), the Single profile dominates such that ideas incorporating critical thinking (Dual) are unlikely to reach the same level as for a single idea unit without instructional intervention.

\section{Teachers' practices}

Nine teachers volunteered a lesson specifically illustrating the teaching of argumentation. Overall the design of their lessons mirror practices identified by Kuhn (2015), only one of which could be considered to promote dialogic perspectives. 
272 Rosedale, McNaughton, Jesson, Zhu, and Oldehaver

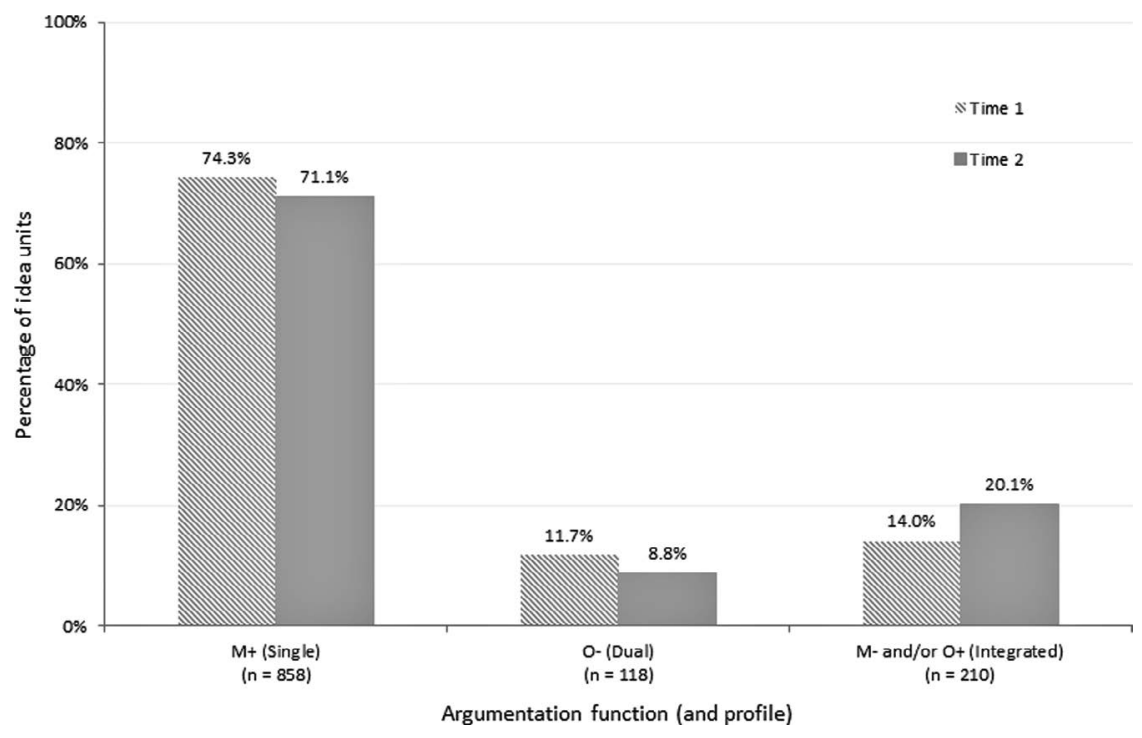

FIGURE 15.2 Distribution of ideas by argumentation function and profile.

There was Coalescent practice in which the goal was consensus building through discussion to achieve synthesis and common ground ("We discuss the answers until we are happy"; "Choose whose is the best strategy"). A second practice was Adversarial, persuading and outperforming others, for example by winning a debate ("So how

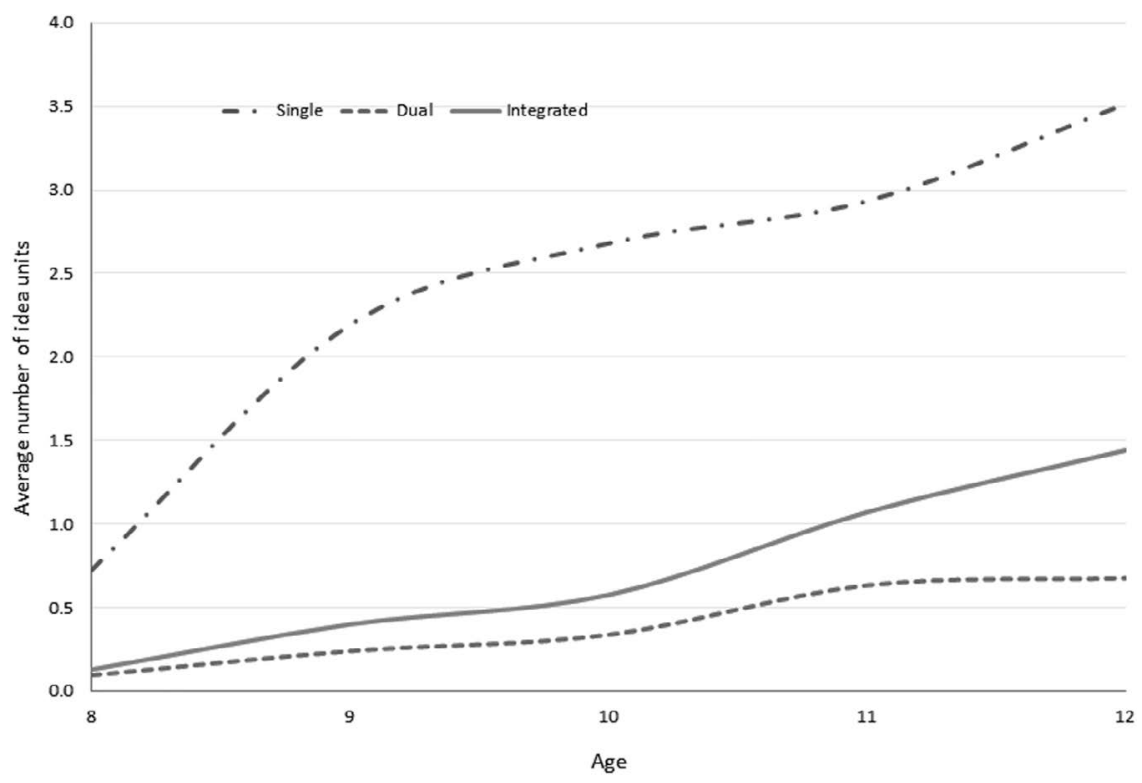

FIGURE 15.3 Trends of average number of ideas across student age by argumentation profile. 
do you win an argument?"). A mixed Coalescent and Adversarial form was observed which involved persuading and deciding on a best solution through a democratic process such as students using a voting protocol to gain agreed position ("Majority wins"). There was one lesson that was clearly focused on dialogic argumentation where the objective was to develop a considered position or solution ("Be open to having your mind changed"). Across all the 38 lessons there were: few instances of explicit teaching to learn sub-skills of arguing or collaboration; little evidence of explicit discussion or deliberate reference to varying perspectives; and limited pushing of student reflection and quality of justifications or positions.

\section{Sensitivity to classroom practices}

The sensitivity of the AT to classroom practices was examined by looking at the association between the proportion of integrated idea units in a classroom and the instructional focus in that classroom. There was a clear association as shown in Figure 15.4. The proportion of integrated idea units was significantly higher in high instructional focus classrooms $\left(p_{T 1}=33.9 \%, p_{T 2}=47.7 \%\right)$ compared with low instructional focus classrooms $\left(p_{T 1}=18.2 \% ; p_{T 2}=30.3 \%\right)$.

The differences in proportion of Integrated profile was significant at each time point as determined by Chi-square tests of independence (see Table 15.3). At both time points, the odds of students having a dialogic perspective (an integrated idea unit) was more than 2 times higher in high focus classrooms.

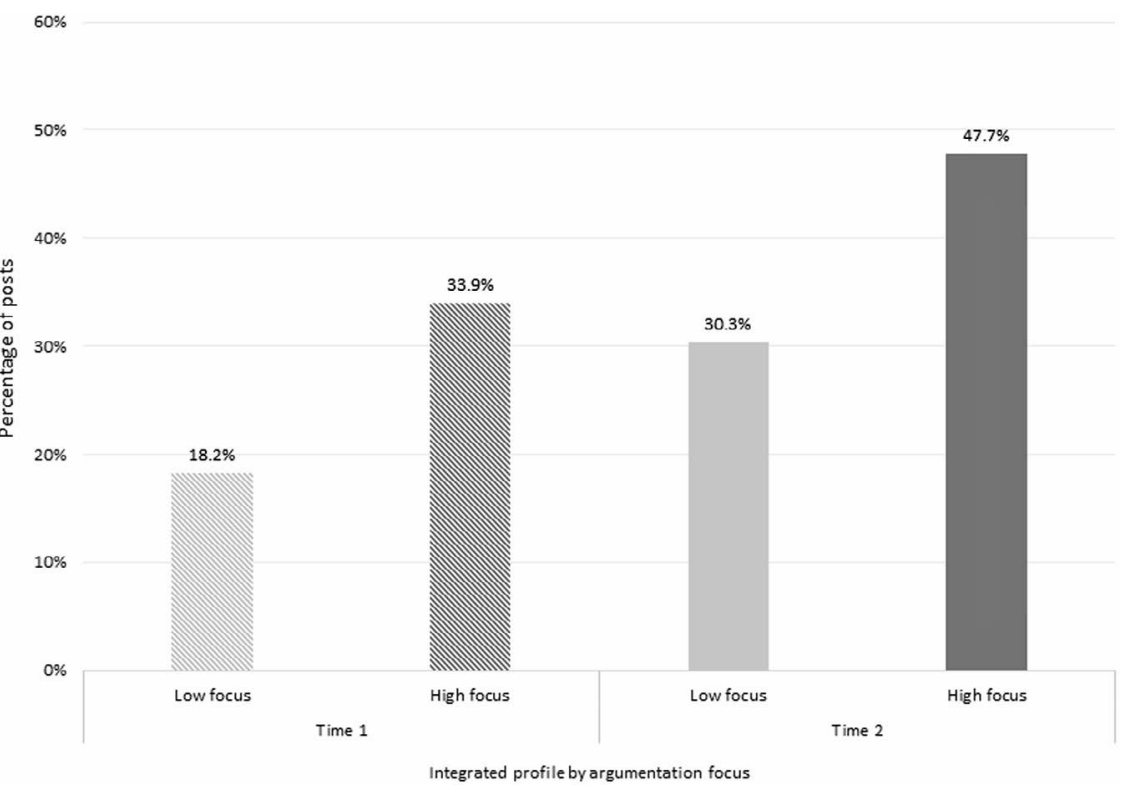

FIGURE 15.4 Percentage of Integrated profile by level of teaching instruction on argumentation skills. 
TABLE 15.3 Chi-squared tests of independence: Level of students' integrated views in online posts and level of instructional focus in classrooms

\begin{tabular}{lll}
\hline Statistics & \multicolumn{1}{c}{ Time 1 } & \multicolumn{1}{c}{ Time 2 } \\
\hline Odds ratio & $2.31[1.09,4.91]^{\star}$ & $2.10[1.15,3.82]$ \\
$\chi^{2}$ & 4.88 & 5.97 \\
P-value & 0.03 & 0.01 \\
\hline
\end{tabular}

$\star 95 \%$ confidence interval in square brackets.

Interestingly, the percentage of Integrated profile improved between Time 1 and Time 2 for both high and low focus classrooms. The result of a $t$-test of two sample proportions showed that improvement in classrooms with low frequency of teaching argumentation were statistically significant at $5 \%(t(197)=2.01, p=.045)$. We have not reported here how the results from Time 1 were fed back to teachers in the schools, nor how especially designed professional development was used to develop the overall teacher resource using the AT. We are currently using case studies of teachers for whom we have data in common at both time points and for whom we have information about their exposure to professional development to answer the question of what the change over time can be attributed to.

\section{Evidence for effectiveness}

We designed the AT to achieve two purposes. One was to reliably assess the internal dialogicity of student argumentation and its development over the primary years. The second was as part of a teacher resource for promoting argumentation. For the latter, we needed to know if the tool as an assessment was sensitive to pedagogy. In this chapter, we have focused on the assessment question and the sensitivity question.

\section{Developmental and diagnostic functionality}

Use of the two versions of the AT two time points offers provisional evidence of the tools' diagnostic functionality related to the Hi-Hi and Lo-Lo patterns (high instruction focus in classroom associated with high integrated perspectives in students' posts). Firstly, replication of the Hi-Hi and Lo-Lo patterns across the two time points suggests evidence of integration in student online argumentation is sensitive to argumentation instruction in classrooms. Both time points demonstrate consistency of integrated student argumentation profiles with higher frequencies of argumentation instruction in classrooms.

Although the pattern is not surprising, given argumentation involves proposing and supporting propositions, it is our view that the AT is purpose built to engage with multiple perspectives, and therefore offers opportunities to stimulate student perspective integration. Teachers would be able to diagnostically 
evaluate their instructional sufficiency in impacting student perspective via the argumentation profiles, particularly in identifying evidence of Integrated profile in student discussion posts. Secondly, the AT (including coding framework and the task) demonstrates consistency in that the two different versions yielded the same pattern of Hi-Hi and Lo-Lo association between instruction and students' Integrated profile. Therefore the AT can be applied with different topics and learning contexts to reliably gauge the sensitivity of student perspective integration to argumentation instruction.

\section{Influence of multiple texts}

Additionally, central to the AT approach is "dialogic" provision of multiple sources of textual evidence, thereby offering a multiplicity of "voices" to stimulate student perspective taking and informed argumentation. Therefore, aside from the discussion board topic that sets up a provocation, one of the key features of the AT design is careful selection of diverse perspectives to fuel attention to alternative evidence and positions. Half of the evidence sources (two texts) confirm or support the perspective of the topic statement, and the balance (two texts) contradict or challenge this view. Students who only demonstrated a single perspective profile bypassed these differences, indicating limitations in their ability to attend to and negotiate the complexity of the issue. On the other hand, inclusion of multiple texts could support (and perhaps prompted) other students to consider the "framework of alternatives," including any dilemmas in reasoning, reliability of source and provision of scientific evidence. The AT is effective in promoting attention to alternatives and therefore more advanced, internally dialogic forms of argumentation.

\section{Discussion}

The early developmental profiles of own position stance in students' argumentation was predicted and aligns with the findings of other studies (Kuhn \& Crowell, 2011). Attention to other perspectives, and counterargument is known to place considerable demand on cognitive capabilities, particularly for younger children, though even young adolescents have been found to concentrate attention on exposition of their own claims, ignoring alternative perspectives, and disconfirming evidence (Kuhn, 2001). That said, the developmental trends in our data reflect some differences from previous studies in the earlier emergence of integrated perspectives, although mainly to consider the merits of other positions, rather than as a critique of one's own position.

This finding of earlier emergence is significant for at least two reasons. The first aligns with Cavagnetto and Kurtz's (2016) view that students may not be as deficient in knowledge of argumentative reasoning skills as prior research suggests (Kuhn, 1991; Kuhn \& Crowell, 2011). The authors maintain that students "argumentative reasoning is heavily influenced by how they interpret the 
task" and this influences the knowledge they bring to bear in response (Kuhn \& Crowell, 2011, p. 628). Our working hypothesis is that the authentic, social context of the AT's discussion board offered students the opportunity to draw on everyday knowledge of argumentative interaction, where attending to the merits of other's views can be both socially validating and informing.

The second reason, is the possibility of digital tools creating developmental pathways to more sophisticated argumentation. Contrary to Kuhn and Crowell's (2011) findings, that a Dual profile (critique to strengthen own view) precedes and may offer a bridge to integration (revise own view), our data suggests the possibility of an alternative progression. It may be that first attending to the strengths in another's position, may offer a bridge to uncovering weaknesses in one's own, or alternatively, confirmation of its strengths. The sequence and focus of attention may be of importance epistemically. For example, the primary goal of an adversarial approach is to first undermine an opponent's position in support of one's own (Walton, 1989), which might be considered epistemically inflexible. Students may be more open to arguing for the purposes of reaching a "better truth" (Wegerif, 2013) where alternative views are negotiated in less "hostile" terms, and critiqued in the service of informed decision making and for co-furthering knowledge. In a New Zealand context, the opportunity for multiple developmental pathways toward more sophisticated argumentation positions is likely to resonate with culturally responsive instructional designs (Berryman, 2013). For example, classroom routines for engagement with digital formats where multiple perspectives are posed will need to take into account the ways family and socio-cultural values influence students' engagement with critique. The consistently low levels of criticality across our student data (e.g., identifying weakness in my or other's reasoning) may be suggestive of wider norms constraining critical forms of engagement. On the other hand, longstanding school practices that promote adversarial debate and persuasive public speaking will undoubtedly have exerted a strong influence on students' argumentation schema as persuasive rhetoric.

The AT, coupled with guided support, offers an effective means to develop students' awareness of the limitations of single perspective argumentation in online contexts, where respectful engagement with difference and healthy forms of intellectual skepticism are 21st-century necessities.

\section{Notes}

1 https://developingindigitalworlds.blogs.auckland.ac.nz/

2 https://developingindigitalworlds.blogs.auckland.ac.nz/tools/online-argumentation/

3 https://developingindigitalworlds.blogs.auckland.ac.nz/teachers/

\section{References}

Berryman, M. (2013). Culturally responsive pedagogies as transformative praxis. Waikato Journal of Education, 18(2), 3-10. 
Brown, A. C. (2016). Classroom community and discourse: How argumentation emerges during a Socratic circle. Dialogic Pedagogy: An International Online Journal, 4. Retrieved from http://dpj.pitt.edu/ojs/index.php/dpj1/article/view/160

Cavagnetto, A. R., \& Kurtz, K. J. (2016). Promoting students' attention to argumentative reasoning patterns. Science Education, 100(4), 625-644.

Crowell, A., \& Kuhn, D. (2014). Developing dialogic argumentation skills: A three-year intervention study. Journal of Cognition and Development, 15(2), 363-381.

García E. (2016). The need to address non-cognitive skills in the education policy agenda. In M. S. Khine, \& S. Areepattamannil (Eds.), Non-cognitive skills and factors in educational attainment. Contemporary approaches to research in learning innovations (pp.31-61). Rotterdam, The Netherlands: Sense Publishers.

Howell, E., Butler, T., \& Reinking, D. (2017). Integrating multimodal arguments into high school writing instruction. Journal of Literacy Research, 49(2), 181-209.

Hutchison, A., \& Reinking, D. (2010). A national survey of barriers to integrating information and communication technologies into literacy instruction. Fifty-ninth yearbook of the National Reading Conference (pp. 230-243). Milwaukee, WI: National Reading Conference.

Kuhn, D. (1991). The skills of argument. New York: Cambridge University Press.

Kuhn, D. (2001). How do people know? Psychological Science, 12, 1-8.

Kuhn, D. (2005). Education for thinking. Cambridge, MA: Harvard University Press.

Kuhn, D. (2015). Thinking together and alone. Educational Researcher, 44(1), 46-53.

Kuhn, D., \& Crowell, A. (2011). Dialogic argumentation as a vehicle for developing young adolescents' thinking. Psychological Science, 22, 545-552.

Kuhn, D., Goh, W., Iordanou, K., \& Shaenfield, D. (2008). Arguing on the computer: A microgenetic study of developing argument skills in a computer-supported environment. Child Development, 79, 1310-1328.

Kuhn, D., Hemberger, L., \& Khait,V. (2014). Argue with me: Argument as a path to developing students' thinking and writing. Bronxville: NY: Wessex.

Kuhn, D., \& Udell, W. (2003). The development of argument skills. Child Development, 74, 1245-1260.

Kuhn, D., Wang,Y., \& Li, H. (2011). Why argue? Developing understanding of the purposes and value of argumentive discourse. Discourse Processes, 48, 26-49.

Litman, C., \& Greenleaf, C. (2017). Argumentation tasks in secondary English language arts, history, and science:Variations in instructional focus and inquiry space. Reading Research Quarterly, 53(1), 107-126.

National Research Council (2012). Education for life and work: Developing transferable knowledge and skills in the 21st-century. Committee on defining deeper learning and 21st-century skills. Pellegrino, J.W. \& Hilton, M. L. (Eds.). Washington, DC: National Academies Press.

OECD (2015). Skills for social progress: The power of social and emotional skills. OECD. Retrieved from https://read.oecd-ilibrary.org/education/skills-for-social-progress_ 9789264226159-en\#page1

Purcell, K., Heaps, A., Buchanan,J., \& Friedrich, L. (2013). How teachers are using technology at home and in their classrooms. Washington, DC: Pew Research Center's Internet E American Life Project. Retrieved from http://www.looooker.com/wp-content/uploads/2013/05/ PIP_TeachersandTechnologywithmethodology_PDF.pdf

Rapanta, C., García-Mila, M., \& Gilabert, S. (2013). What is meant by argumentative competence? An integrative review of methods of analysis and assessment in education. Review of Educational Research, 83(4), 483-520.

Reznitskaya, A., Anderson, R. C., McNurlen, B., Nguyen-Jahiel, K., Archodidou, A., \& Kim, S.Y. (2001). Influence of oral discussion on written argument. Discourse Processes, 32(2-3), 155-175. 
Roberts, R. D., Martin, J., \& Olaru, G. (2015). A Rosetta Stone for noncognitive skills: Understanding, assessing, and enhancing noncognitive skills in primary and secondary education. New York: Asia Society and ProExam.

Saltarelli, A. J., \& Roseth, C. J. (2014). Effects of synchronicity and belongingness on faceto-face and computer-mediated constructive controversy. Journal of Educational Psychology, 106(4), 946.

Song,Y., Deane, P., Graf, E. A., \& van Rijn, P. (2013). Using argumentation learning progressions to support teaching and assessments of English language arts. RED Connections, 22, $1-14$.

Voogt, J., \& Roblin, N. P. (2012). A comparative analysis of international frameworks for 21st-century competences: Implications for national curriculum policies. Journal of Curriculum Studies, 44(3), 299-321.

Walton, D. N. (1989). Dialogue theory for critical thinking. Argumentation, 3(2), 169-184.

Wegerif, R. (2013). Dialogic: Education for the Internet age. London: Routledge.

Wilkinson, I., \& Son, E. (2010). A dialogic turn in research on learning and teaching to comprehend. In M. Kamil, P. Pearson, E. Moje, \& P. Afflerbach (Eds.), Handbook of reading research (pp. 360-387). New York: Routledge.

Woolley, S. C. \& Howard, P. N. (2017). Computational propaganda worldwide: Executive summary. In S. Woolley \& P. N. Howard (Eds.), Working paper 2017.11. Oxford, UK: Project on Computational Propaganda. Retrieved from http://comprop.oii.ox.ac.uk/ wp-content/uploads/sites/89/2017/06/Casestudies-ExecutiveSummary.pdf 